\title{
Evaluating Circular Economy under a Multi-Parametric Approach: A Technological Review
}

\author{
Grigorios L. Kyriakopoulos ${ }^{1}$ (), Vasilis C. Kapsalis ${ }^{2, *} \mathbb{C D}^{\text {, Konstantinos G. Aravossis }}{ }^{2}$, \\ Miltiadis Zamparas ${ }^{3}(\mathbb{D})$ and Alexandros Mitsikas ${ }^{2, *}$ \\ 1 School of Electrical and Computer Engineering, Electric Power Division, Photometry Laboratory, \\ National Technical University of Athens, 15780 Athens, Greece; gregkyr@chemeng.ntua.gr \\ 2 School of Mechanical Engineering, Sector of Industrial Management and Operations Research, \\ National Technical University of Athens, 15780 Athens, Greece; arvis@mail.ntua.gr \\ $36^{\text {th }}$ Region of Healthcare Authority: Peloponnese, Epirus, Ionian Islands and Western Greece, Ipatis 1, \\ 26441 Patras, Greece; mzamparas@upatras.gr \\ * Correspondence: bkapsal@mail.ntua.gr (V.C.K.); almitsikas@gmail.com (A.M.)
}

Received: 19 September 2019; Accepted: 1 November 2019; Published: 4 November 2019

check for updates

\begin{abstract}
A circular economy (CE) is conceptualized under different rounds of materials and energy cycling flows and is a matter of a three-level deployment: inter-enterprise circulation, regional circulation, and social circulation. Regarding them, the aim of this research was to get an update on the current technological advances and the perspectives of its implementation. Thus, a multi-parametric approach has been conducted to analyze the functionality of technologies in wastewater treatment, organic waste management, agrarian development, and food waste in the context of CE. Beside the narrative of the technological view, a critical approach assimilates the environmental, marketing, economic, governmental, and procedural viewpoints and leads to key indicators which are subject to positive and negative externalities. Due to this co-existence, we denoted the complexity of CE principle implementation and the need for specific envisage in each case, while proposing strategies are formulated in the light of social-environmental impact. Finally, further research gaps were proposed for deeper consideration.
\end{abstract}

Keywords: agri-food products; circular economy; food waste management; industrial symbiosis; negative externalities; resources; social-environmental impacting; technological nutrients; waste management

\section{Introduction}

\subsection{Evolutionary Definitions and Designing Features at the Circular Economy Framework}

Circular economy (CE) is known as a "closed loop" economy, in which the industrial and social evolutionary concepts aim to achieve holistic sustainability goals in relation to a no waste philosophy. It aims for a regenerative system in which waste and input energy are minimized. This can be achieved through the (re)design of maintenance, repair, reuse, remanufacturing, refurbishing, and recycling. CE has attracted increasing research interest, with an almost exponential growth in publications. This reflects the increased interest from companies and policymakers in Europe, China and other regions [1].

The managerial conceptualization of CE is considered in the works of McDonough and Braungart, Stahel, and Lovins [2]. Under the principles of CE, products and materials approaching their end-of-life stage can be regenerated or restored or replaced.

The CE also refers to industries shifting in favor of renewable energy, causing toxic chemicals and waste elimination, while its advantages are driven by the superior design of materials, products, 
systems, and business models [2]. Other CE benefits are determined by the entrepreneurial sector, where businesses can benefit through material savings, supply risk reduction, customer loyalty improvements, and new revenue streams opening [2].

Product-service systems (PSS) are a specific type of value proposition that a business (network) offers to (or co-produces with) its clients. They are one of the most effective instruments for moving society towards a resource-efficient CE. The advantage of PSS thinking is that it moves away from existing product concepts, and focuses on the final need, demand, or function that needs to be fulfilled. Product-service systems (PSS) have been developed for more than fifteen years. However, they have still not been widely implemented, due to various reasons (for example, consumer culture; [3,4]).

Special implementation practices for CE transforms the ways in which manufacturing industries do business. However, challenging preconditions towards a successful CE necessitate production and consumption systems, as well as the standard approach for creation, fabrication, and commerce of products. In this framework, four principles of $\mathrm{CE}$, pointing towards resource depletion and materials valuation at the industrial sector, have been proposed by the Ellen MacArthur Foundation [2]: (1) Optimization of resources and energy uses throughout life cycling, (2) Products and components maintenance and use for longer periods, (3) Systematic cycling of materials as many times as possible through cascaded uses, and (4) Pure materials use to improve the quality of post-life use. Therefore, the paradigm shift of the $\mathrm{CE}$ topic has gained recognition as the way forward to harmonize economic growth with environmental issues and resources scarcity [5].

Indicatively, there are loops where companies conserve their assets during their lifecycle, being not disposed in landfills for the longest possible period. Other loops are referred to as resource adoption, reintegration into nature, or feedstock into subsequent supply chains. Such conceptualization of $\mathrm{CE}$ is driven by organizational changes of modeling production and consumption, while advancing developmental changes in the ways that industries profit and overall economic activities are transacted [2].

De los Rios and Charnley [2] signaled a challenge to reduce the dependence of new products' resources. Other challenges reveal the influential role of designing consumer behavior against both the careless depletion of resources and the superficial changes in products $[2,6]$.

Based on the literature production, evolutionary definitions, and designing features of $\mathrm{CE}$, Gregorio et al. (2018) analyzed publications that have been grouped at the concepts of circular economy (CE), green economy (GE), and bioeconomy (BE), all of which are linked by the common objective to promote sustainable development. These CE, GE, and BE concepts were developed in the 1970s and the 1990s. However, it was not until the beginning of 2004 that they became popular in the economic context. Specifically, regarding $\mathrm{CE}$, the number of publications and their geographical dispersion have increased considerably since 2009, while in China it was reported the majority of published studies abided to the 2008 passing of a National Circular Economy Law. Following the approval of the EU Action Plan on CE in 2015, a publication increase is expected to continue in these countries [7].

GE is considered a tool to "improve human well-being and social equity, while significantly reducing environmental risks and ecological scarcities" [7]. GE is designed to implement economic models and to generate profit while avoiding environmental degradation, enhancing eco-innovation, improving resources and waste management, as well as reusing of raw materials and supporting the transition towards sustainable consumption and production [7].

$\mathrm{BE}$ is considered a tool which was introduced in 1971 by the economist Georgescu-Roegen, stating that "the economy must be a branch of biology ....... we are one of the biological species of this planet and as such we are subject to all the laws that govern the existence of terrestrial life" [7]. These authors denoted that the European Commission defines BE as "an economy that covers the production and use of renewable biological resources (land and sea) and the conversion of these resources and waste into value-added products, such as food, feed, biological products, and bioenergy" [7]. BE has been structured on the more efficient use of resources, reduced dependence on non-renewable resources, mitigation of climate change, ensuring feedstock and security, thanks to the use of renewable resources for industrial 
purposes, the feasible competitiveness, and employment developed among companies. At a global level, the increased trend of BE adoption and strategies in recent years is noteworthy [7].

In the scientometric study of [7], it was shown that the existing literature is rich in analyzing implemented policies and issues related to more sustainable modelling paths and research in China and the EU. Specifically, the general analysis upon definition related to the CE framework was accompanied by the evolution of environmental policies to mitigate climate change and develop CE. Existing practices on eco-design unveiled that there is little research in this field. Besides, eco-design directives should include more environmental aspects and focus on resource efficiency, recommending that efficiency indicators should be established. Moreover, within the EU, policy design and analysis were mainly focused on recycling and fostering its relationship with ecological design ([7,8]).

\subsection{Review Orientation and Reasoning}

Nowadays, the continuing reserve reduction of natural resources without replenishment runs the risk of ecological collapse. Besides, unwise management of natural capital entails a social and economic responsibility, while sustainability depends on its maintenance. Subsequently, the convenient economy model of "take, make, consume, and dispose" is insufficient; thus, consumers, governments and businesses must be aware of this reality. Contrarily, feasible production and consumption should be valued through the efficient use of resources, energy modes of production, and waste reduction. This scientific direction impacts the creation of new products, increases competitiveness in new markets, and promotes sustainable economic growth and employment without causing environmental depletion [7].

From a sustainability viewpoint, if the $\mathrm{CE}$ aims at achieving sustainable development goals, research concepts are proposing solutions to produce more cleanly without generating waste or gas emissions, use materials and resources efficiently, and respect nature. Therefore, entrepreneurial policy makers should take into consideration the importance of CE planning for their businesses [7]. From a literature viewpoint, there have been assessments done in the construction industry, adopting industry-specific methods for measuring performances of building materials, by combining a real estate appraisal with LCA. Alternatively, the analytic hierarchic process (AHP) is a multi-criteria decision making method to derive ratio scales (derived from the principal Eigen vectors) from paired comparisons. AHP can be adopted as a basis for implementing a sustainability assessment framework for modular buildings and comprehensive evaluation on the CE performance of eco-industrial parks [9]. In this research approach, a set of economic and environmental indexes was developed, enabling the calculation of several sustainability performance criteria (SPC) to support designers during decision-making processes. Other $\mathrm{CE}$ frameworks use factor analysis to develop a $\mathrm{CE}$ evaluation index based on information about energy consumption, resource recycling and reuse, environmental protection, as well as costs and social parameters [9].

From a geographical viewpoint, a comparative study on implementing the CE in China and the EU determined that the Chinese perspective has emerged as a response to rapid industrialization and increased contamination of wastes, caused by the use of resources. In Europe, the CE falls within the field of wastes and it can be focused mainly on companies. Although both China and the EU believe that the indicators are essential, none have as yet been defined by the European Commission, so China's indicators could potentially be considered by the EU [7].

From a complex socio-environmental viewpoint, the depletion of resources and the downgrading of the environment-driven by globalization and consumerism phenomena-are attracting interest to the $\mathrm{CE}$ concept worldwide. Fostering the substitution of the end-of-life notion with restoration and closed-loop product lifecycles, CE aims to eliminate wastes, retain the value embedded into products and materials, enhance the use of renewable energy sources, and eliminate toxic chemicals. However, the measurement and the assessment of circularity performances are not yet a common practice in companies, even though CE research has continuously evolved within the last few years, which has led both researchers and practitioners to understand how to measure and quantify its impact in a real context. Shortage of interest in the CE performance assessment area and lack of methodologies able to 
consistently measure and gauge concurrently, all necessitate that the variables involved in a circular system have to be registered [9].

From the procedural viewpoint, CE interrelated with sustainability, seeking to keep the value of resources in the economy as long as possible, to minimize waste generation and transform it into resources, and to reintroduce these resources into production processes. For this purposes, resource identification differentiates biological (biodegradable) nutrients from technological (designed for reuse or recycling) nutrients [10].

The aforementioned multifaceted situation is briefly outlining the current scientific framework of $\mathrm{CE}$ analyses in the relevant literature production. However, the majority of these review approaches of $\mathrm{CE}$ are scientometric studies, in which published papers of CE-orientation were collected and treated at geographically-dispersed and thematic-allocated groupings. Contrarily, in this review paper it is the first time (as we are aware of) where a systematic literature review was conducted to detect the scientific paths on which existing CE assessment methods are proposed and performed, addressing technological and socio-economic impacts. Therefore, this review study was based on key findings and an integrated positioning framework was developed to measure and to jointly assess the circularity degree and significance from these literature-unique technological and socio-economic viewpoints of investigation.

This review study was structured as follows. In Section 2, the functionality of CE was developed in the field of wastewater management; while in Section 3, the evaluation of resources in the context of CE was determined by the analytical tools of multi-criteria decision making (MCDM), the life cycle assessment (LCA), and the energy-water-food nexus towards a cleaner future. Then, Section 4 has been devoted to technologies developed in the context of specific industrial processes: the petrochemical industry and biological drying. Due to the significance of specific wastewater types in accordance with $\mathrm{CE}$, these types were addressed in distinct sections: organic wastes (Section 5), agrarian development (Section 6), food waste management (Section 7), and human wastewater stream nutrients (Section 8). Subsequently, the main strategies and the socio-environmental impact were holistically addressed in Section 9, while the review study ends in Section 10, where the current situation, the future propositions, and the future research paths of CE are denoted.

\section{Functionality of Circular Economy at the Context of Wastewater Management}

CE was conceptualized in 1990 and it was a response to the desire to substitute the prevailing traditional linear economic model with a circular one whose principal aim is to keep the value of products, materials, and resources in the economy for as long as possible. This model minimizes waste and the consumption of resources and foresees that goods generate value through their use at the end of their useful life. CE is based on four principles, the so-called 3Rs-reduce, reuse, and recycle-and a fourth principle, sustainable design strategies to achieve greater durability in the designed products, incorporated by the Ellen MacArthur Foundation [7]. CE is an aspiration without borders. To get a real CE model from the current linear economy model, the following steps must be taken: reuse, recycling, recovery, and prevention. Reuse is the first step to start the transition to the $\mathrm{CE}$, but prevention is the most important step in this new paradigm. Waste management is currently carried out in the following order: production, presentation, collection, transport, and treatment. According to Argudo-García et al. [10], all waste should be reused, and for that, CE aims to minimize the elimination [10].

Among the aforementioned change strategies, the principle of the 3Rs-reduce, reuse, and recycle - unveils that waste hierarchy lists different options for managing waste from an environmental perspective, from best (waste prevention) to worst (disposal). In this context, Directive 2008/98/EC established two main objectives for EU waste legislation: waste prevention and development of a "recycling society" [10].

Waste prevention has been and continues to be the first and most important objective of EU waste management policy. Developing a recycling society implies reducing the environmental impact 
of resource use and improving the resource efficiency of such use. This approach not only avoids producing waste, but also uses it as a resource [10].

Based on the processes of resource input, enterprise production, product consumption and abandonment, $\mathrm{CE}$ is a cycle economy of closing materials which is continuously improving the efficient use of resources, transforming traditional economic development (being reliant on the linear increase of the net consumption of resources) towards circular economic development (being reliant on ecological resource circulation), as shown in Figure 1.

Although the strategy to improve the commitment of all actors of supply chains is still a challenging issue, yet, little is known about consumer behavior drivers that are to be engaged in closed loops within natural ecosystems [11,12]. It is exemplary noted that while supporting the CE in urban areas and converting organic waste into organic fertilizers, there is great potential to close the biodegradable waste loop [10].

For example, in the food sector, an interesting feature of $\mathrm{CE}$ is gaining maximum value from food waste while re-circulating within food supply chains [11]. Circularity can also be perceived in various ways in lesser-utilized remanufacturing [13]. The corresponding research may contribute in novel perspectives of sustainable energy and material flows through ecosystems and close the broken cycles, taking into account the risks associated in the inter and intra organizational interactions and the underlined risks $[14,15]$.

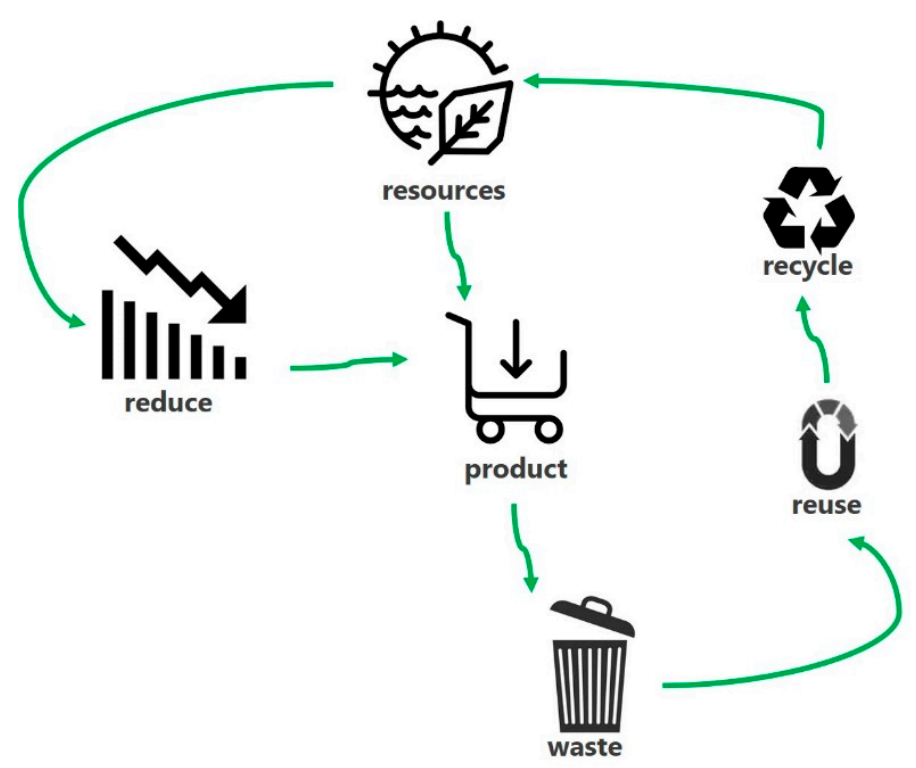

Figure 1. Basic mode of CE deployment. Source: adapted and modified from Wang [16] p. 1424.

$\mathrm{CE}$ is composed of three levels: inter-enterprise circulation; regional circulation (mainly referring to industrial park circulation); and social circulation (mainly referring to the circulation between enterprises and society) [17]. The generally considered evaluation methods for judging circulation at each level is shown in Table 1: 
Table 1. CE conceptualization and evaluation methods. Source: adapted and modified from Wang [16] p. 1424.

\begin{tabular}{cl}
\hline Evaluation Method & \multicolumn{1}{c}{ Conceptualization } \\
\hline Life cycle & $\begin{array}{l}\text { Valuation of the environmental impact at each one step of } \\
\text { the product life cycle. }\end{array}$ \\
\hline Clean production; Auditing & $\begin{array}{l}\text { Standardization of procedures; investigation and diagnosis } \\
\text { of production process; finding of high pollution reasoning, } \\
\text { increased consumption, low efficiency; planning and } \\
\text { promoting strategies of cleaner production and } \\
\text { technologies of improved production. }\end{array}$ \\
\hline Material flow analysis & $\begin{array}{l}\text { Determination of material flow, diffusion, and utilization at } \\
\text { urban contexts, in quantitative terms. }\end{array}$ \\
\hline
\end{tabular}

\section{Evaluation of Resources at the Context of Circular Economy}

With the plan to make European businesses cleaner and more competitive, the EU adopted an ambitious new Circular Economy Package, in which ambitious measures were delivered to cut resource use, reduce waste, and boost sustainable production and consumption [18]. In this respect, assessment methods can be focused on resource recovery from waste within a CE context, with a need to consider aggregated values such as environmental, economic, social and technical domains towards an integrated approach [19]. In Figure 2, suitable metrics can evaluate the "complex value" of materials, components, and products by holistically summing up their environmental, economic, social, and technical benefits and impacts across the system [20].

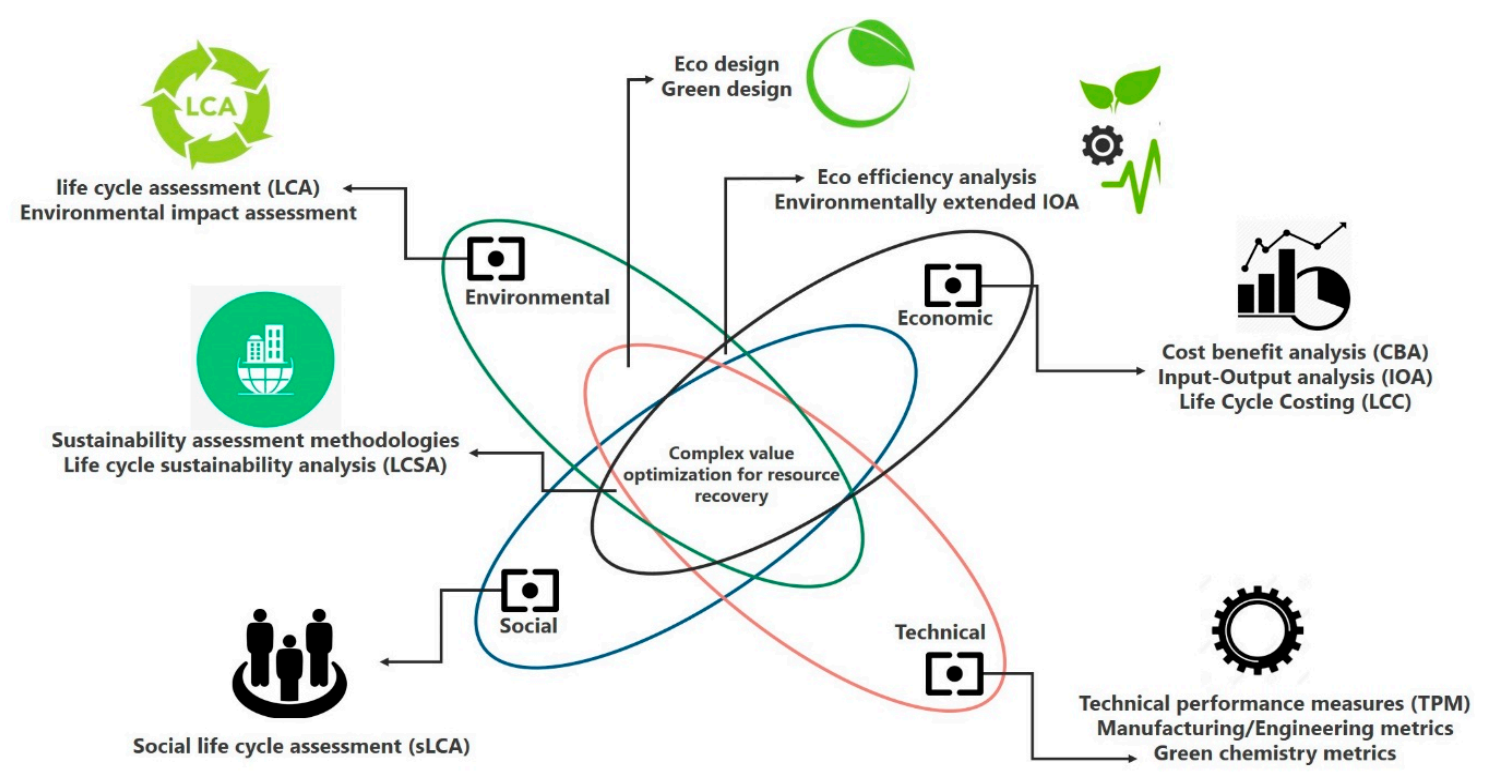

Figure 2. Framework of methods, tools, and domains, in appreciation of research value. Source: adapted and modified from Iacovidou [20], p. 931.

In solid waste management, there are several types of decision-making processes; among them the most widely used are that of life-cycle assessment (LCA), cost-benefit analysis (CBA), multi-criteria decision making (MCDM) [21], as well as the energy-water-food nexus towards a cleaner future by improving CE [22]. LCA is an analytical assessment of the environmental performance of products or services over their whole life cycle, including resource consumption, production, utilization, and disposal. The key technical metrics of "recyclability" are of great importance in resource recovery from waste (RRfW) systems. Based on Figure 3, it is noteworthy that with solid waste management the aforementioned decision support frameworks—LCA, CBA, MCDM-are linked to each other. 
Specifically, LCA only considers potential environmental aspects when evaluating waste management systems and ignores other decision-making options such as the economic and social effects. CBA is a monetary valuation method, the main goal of which is to maximize economic efficiency. CBA analyzes costs and benefits, including economic aspects, natural resources, and environmental impacts due to waste minimization-which can be especially introduced in emerging countries where open dumping and open burning are the main waste treatments implemented [10], waste recycling, and the by-products of waste treatment [21].

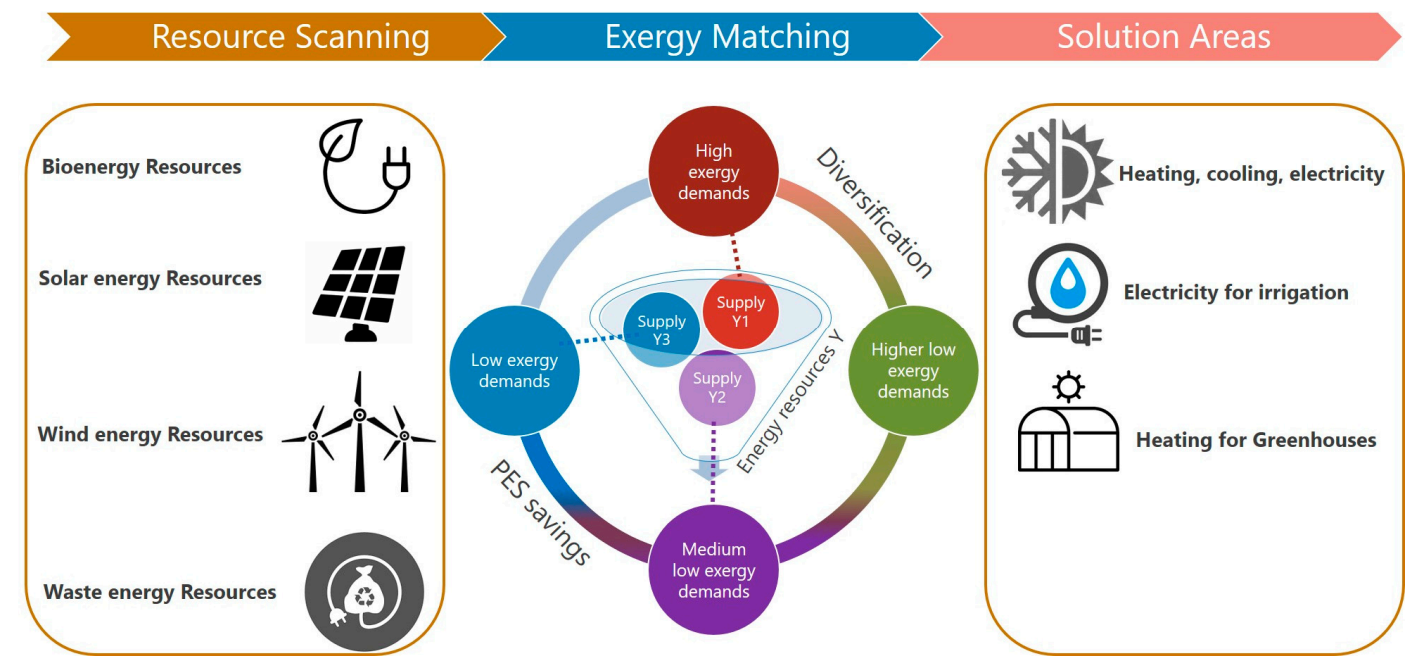

Figure 3. Mind map of developing CE based on the operation of a dairy farm. Source: adapted and modified from Kilkis and Kilkis [22] p. 1088.

Holistic methodologies are able to systematically and practically measure and assess the circularity degree of a given system and take in account all the heterogeneous resources involved in its lifecycle. Hence developmental opportunities can be paved on the framework conceived based on a set of key performance indicators (KPI) suitable to the assessment of the circularity performance. These KPIs can deal with the circularity degree of the resources within the product life cycle and can also support the quantification of those that are the economic and environmental benefits of the CE. From a company's portfolio circular innovation perspective (both for completely new products and incremental improvement of existing products), these circular KPIs can support not only the decision making process along the design of new products but also the comparison of different versions of the same product based on their degree of circularity and the benefits they can bring. Companies would be able to compare different products based on their circularity and on benefits they can achieve [9]. Besides the aforementioned performance indicators, environmental indicators have also been introduced in the urban areas, serving as routes of sustainable development in waste management and supporting the following features [10]:

- Indicators are considered as basic tools in the provision of information about the state of the environment, thus contributing to awareness among public authorities and the population in general.

- Indicators can be used in the preparation and the evaluation of environmental policies.

Therefore, CE indicators can be defined and calculated in order to reintroduce urban solid waste from urban areas into the CE context. Thanks to these indicators, a clear framework of the environmental situation can be determined in the urban areas where it is applied-a standardized collection of generated waste data, the ease of adaptation to the management of environmental policies, as well as the performance of regular comparative analyses about waste generation [10].

At the following sections, the decision-making processes of MCDM and LCA were deployed in a detailed manner. 


\subsection{Multi-Criteria Decision Making (MCDM)}

Assessment via MCDM considers more than just two pillars of sustainability, focusing on environmental, economic, social, and technical aspects $[19,21,23]$. Because it analyzes multiple conflicting criteria, MCDM is regarded as a complete method and the most effective decision support framework when evaluating existing or potential alternatives [21]. MCDM is a decision support framework that has the ability to assess and evaluate multiple conflicting criteria and it uses a different methodology to conduct a pairwise comparison. MCDM can be applied in any discipline to make effective and accurate decisions based on various evaluation criteria. Using the MCDM system can result in improved outcomes and more comprehensive support for the decision makers and validity to the stakeholders [21].

\subsection{Life Cycle Assessment (LCA)}

LCA is also a required decision tool in the CE context [24]. Current developments of research aim to extend the analysis upon organizations' costs and benefits, taken into consideration the multifaceted entrepreneur features of the CE. Furthermore, the full evaluation of novel technologies in certain value chains may be favored in increasing production but at the same time they are proven inefficient to harness waste energy, in terms of circular design and recycling of nutrients [25].

LCA can effectively contribute to the development of industrial ecology (IE), while supporting societal and environmental interrelations. In turn, IE can strengthen sustainable CE contexts while creating different alternatives of materials and their wastes through reuse, repair, recycling, and recovery of components with their materials [26]. It is noteworthy that products designed on the basis of $\mathrm{CE}$ principles are not necessarily leading to minimum environmental impact. Where they manage to close material cycles, life cycle assessments show that their overall environmental impact is often higher than the non-circular design. For example, electronic consumer products have shown that recovering all the materials present in a certain product in their original grade is possibly creating substantial additional environmental impacts $[27,28]$. Moreover, industrial symbiosis requires CE technologies to embed functional and accountable approaches in order to overcome the barriers of sunk costs and irreversible decisions [14].

Indeed, by analyzing resource flows, it is feasible to identify solutions to reducing environmental impact and, at the same time, generating economic savings. However, CE does not mean only industrial symbiosis and systemic optimization, but also life cycle optimization. A self-regenerating economy is necessary to work at a system level and at a single product level at the same time, with the perspective to go into detail to analyze the single production phase and the single resource flow. This way, it is possible to understand the improvement paths, while modeling could further keep the product as the protagonist of the analysis in terms of $\mathrm{CE}$ and to calculate its circularity degrees [9]. The sparse literature analysis regarding the overall evaluation of $\mathrm{CE}$ benefits unveils the difficulty of researchers in considering the large number of different variables composing of and called for along the entire lifecycle of a system (LCA), affecting different levels of analysis (environmental, economic, and social) [9]. However, not only single companies but also industrial parks, global supply chains, urban territory, and municipal solid wastes can be taken into account, giving researchers a chance to approach very different contexts in which circular business models have been adopted and their combination with those more commonly used in the circular context but also the industrial symbiosis level considered, by several types of industries [9].

\subsection{The Energy-Water-Food Nexus towards a Cleaner Future of Improving Circular Economy}

In higher education universities, the accelerating pedagogical innovation to enable a more sustainable future is one of the main responsibilities based on the integration of CE system principles with three phase energy policy courses, as depicted in Figure 3. However, policy makers are also concerned with alternative scenarios applying the three-phased method: energy resources scanning, 
exergy matching, and evaluation among different solutions [22]. Subsequently, critical remarks for future consideration are related to the economic costs, the dynamic perspectives, the technological progresses, and the public incentives offered [22]. Scaling up these projections in real-world contexts is a target for the application and synthesis of knowledge on environmentally-driven CE systems [22].

\section{Technologies Developed in the Context of Waste Management and the Circular Economy}

\subsection{Composting Technology and Recovery of Nutrients from Urban Waste Management}

From a literature viewpoint, it has been reported that many Asian cities have been exposed to health risks because the majority of their heavily polluted water has been dumped into freshwater streams. The technology of recycling and composting organic waste could turn wastes into valuable resources, simultaneously supporting the restoration of degraded lands, the reduction of chemical fertilizer imports, and the improvement of food security [29,30]. One of the major advantages of land filling is the simplicity of implementation and operation as well as the ability to adapt to fluctuations in the quantity or composition of the wastes and, thus, it was proven a feasible process to use to treat municipal solid waste (MSW) [31]. However, organic waste disposal in landfills has created various environmental issues such as greenhouse gas emissions and leachate. Awareness is a contentious socio-environmental issue that has resulted in diverting landfill to compost. Thus, there is a need to develop an analytical tool to select the best composting technology. Assessing the available composting techniques for organic waste management is complex and complicated. While most waste management models consider environmental and economic aspects, very few consider social and technical aspects. The emphasis on social and technical aspects in the decision-making process has developed in recent years [21]. Therefore, to ensure the sustainability of the decision support framework regarding composting technology for organic waste management, all four criteria (environmental, economic, social, and technical) need to be evaluated [11], as briefly addressed below.

From an environmental viewpoint, environmental issues have directed society to find alternatives to manage the organic waste disposal process instead of using landfills. One direction is given by the composting process which may be used for biological decomposition, simultaneously managing organic waste and transforming a fraction into valuable products and minimizing pollution [21]. However, the assessment of several options needs to be taken into account before the implementation, as well as at the end product stage. Namely, the requirements of sources of waste feedstock in terms of scale, quality of input and output, site location and area, operational management skills, and capital and operating costs have to be thoroughly considered [20].

From a marketing viewpoint, the financially feasibility of composting succeeds by trading extra supply of the producible compost and transferring the recovered nutrients from urban areas to rural areas, in alignment with moderation of logistics transportation cost and preservation of high quality of compost soil $[21,30]$.

From an economics viewpoint, compost demand and organic farming in agriculture may replace the elimination or reduction of government subsidies to chemical fertilizers and improve the organic crops in foreign markets with long-term contracts [30].

From a governmental viewpoint, the composting choice aids in nutrients recovery and can reduce public expenditures. Besides, the monitoring and certification of compost will facilitate compost markets. Conclusively, central governmental policies can affect appropriate institutional regulations and training programs to support financial incentives and raise environmental awareness upon recycling [30].

From a procedural viewpoint, specific decisions must be made based on these various criteria. The decision maker needs to understand the assessment steps required to make the best decision and to identify the specific weaknesses and strengths of that decision. Assessing the available composting techniques for organic waste management is complex and complicated. While most waste management models consider environmental and economic aspects, very few consider social and technical aspects. 
The emphasis of social and technical aspects in the decision-making process has developed in recent years [21]. The evaluation of the four criteria of environment, economic, social, and technical aspects can ensure a sustainable decision support framework aiming to decrease the probability of mistakes and risk during the process planning and execution phases. Such a sustainable decision support framework is associated with the evaluation of each technology proposed to policy makers, so that the optimal alternative can be identified [21].

The future opportunities and further research orientations of composting plans in the agriculture sector are offered to model the equilibrium point in terms of food supply security [21]. Another significant remark is that future research can characterize wastes according to its potential for reutilization in order to be constituted as future technological nutrients in other productive processes, thus considering its management within the $\mathrm{CE}$ context, which could be achieved if each of the majority fractions of urban wastes (organic, paper, textile, plastic, and old tires) can be exploited. Thus, policy makers and urban designers should structure a scorecard of indicators that can facilitate the decision making process to manage the current negative externalities with these waste products. Subsequently, waste management should be considered as the use of technological nutrients within the CE context that foster the evaluation of the progress of sustainability in terms of reduction, reutilization, and recycling of the waste generated, thus effecting the conversion of the actual linear economy [10]. Out of an urban context, family businesses can manufacture new products for the community, following cradle to cradle principles. This methodology preserves resources by employing technological nutrients, while the model maintains the useful life of the resources. Subsequently, the negative externalities created by the family businesses will diminish. The transition to the new model can be gradually completed when business production follows CE principles [18].

\subsection{Technologies in Refuse Derived Fuel and the Organic Rankine Cycle}

Refuse derived fuel (RDF) is produced by solid and urban waste treatment, aiming at (a) analysing the energy recovery properties of the reject fraction from biological-mechanical treatment plants, and (b) developing recovery techniques before sending it to a landfill [32] to reduce emissions and waste energy loss [33]. Furthermore, RDF briquettes are reported to be utilized in the gasification system, being recovered by plastic waste from dumpsites [34]. Therefore, in the relevant literature, there are plenty of technologies for optimization of the RDF technique. Particularly, the catalyzing effect of chlorine depleted pyrolyzate on RDF combustion performance was reported [35,36]. The best combustion characteristic was obtained when the dosage of chlorine depleted pyrolyzate was $10 \%$ $w / w$ RDF [36]. The same optimum 10 wt. $\%$ RDF-derived char addition to two-phase olive mill waste prior to slow pyrolysis was reported by Manya et al. [37], that supported an apparent increase in the carbonization efficiency as well as an enhancement of the resultant char's reactivity in air [37].

Similarly, Younan et al. [38] studied a selected species/mixture of cellulose and hemicellulose, a mixture of polystyrene and polyethylene terephthalate, and a mixture of polyethylene and polypropylene. In the relevant materials-oriented literature upon RDF, it was also argued that the combined effect of plastics, chlorine content, and food waste can accelerate the thermal decomposition of refuse-derived fuels and fuel blends. Variable mechanical treatments applied, such as shredding or extrusion, are applied to MSW to produce RDF [36]. The need of full investigation into the chemical composition of the urban waste before using solid waste in place of fossil fuels should be stressed [33].

Another technology to waste heat recovery for generating electricity is the organic rankine cycle (ORC). The designing parameters of ORC units are the cost-effectiveness which are determined by fuel pricing and the net present value, and the technical parameters of ORC units are that of nitrogen oxides and sulphur oxides emissions, the high or low-pressure of selective catalytic reactors (or exhaust gas recirculation units), as well as the volume of the heat exchangers. ORC features are proven suitable for electricity production [39] in different configurations which determine the exergoeconomic performance $[40,41]$. 


\subsection{Petrochemical Technology and Waste Management}

The development of technologies for liquid waste treatment at petrochemical industries is an important task. In the relevant literature, the development of $\mathrm{CE}$ is an important measurement objective of China, to implement the scientific concept of development and to construct environmentally-friendly and resource-saving enterprises, and it is an objective need to guarantee the sustainable development of petrochemical enterprises [16]. Shortage of resources and energy —vigorously adjusting industrial structures and promoting transformation and upgrading - is an arduous task of chemical groups to further develop CE. At present, research of a CE evaluation index system in the petrochemical industry is mainly on qualitative analysis, which cannot reflect the development level of CE in the chemical industry. Therefore, in order to promote the development of CE in the chemical industry, a more targeted and quantifiable index system should be based on AHP [16] which has also been implemented in many sectors, such as health care management [23], food industry [19], or rock minerals [42] and mining [43], to name some.

The index system of CE is the theoretical basis for formulating the development goal and plan of $\mathrm{CE}$, and it is also a quantitative evaluation tool for assessing the effect of $\mathrm{CE}$. The development goal of $\mathrm{CE}$ is to achieve the balance between environmental protection and economic development on the basis of making full use of resources and energy and reducing pollution emission to the maximum extent [16]. Among the many available methods, the AHP is widely used at present.

The key evaluation indicators that arouse the functionality of $C E$ in the petrochemical industry should follow the following principles of circular economic evaluation index; systematic, scientifically sound, operable, and cohesive [16]:

- The CE-evaluation was determined by a multi-index comprehensive evaluation method. This is an index scoring method based on weighted average, which combines the single index evaluation value (a dimensionless result) of multiple indexes into one (or several) comprehensive evaluation value by means of weighted average. The advancements of this method are that of conciseness, intuition, clear conclusion, and strong maneuverability. Besides, the resource utilization rate of solid waste in the petrochemical industry is determined by crude oil, coal, natural gas and electric power, while the output value of the aforementioned comprehensive utilization products of "waste-types" are that of the industrial output value per unit energy source, the resource utilization efficiency, and the recycling utilization rate of resources, being all improved (at the reference period of the study reviewed).

- The rate of change in the final disposal of industrial waste and the caused environmental pollution are very unstable.

- Pollution of the atmosphere and water resources should not be ignored.

- The petrochemical industry is an intensive industry with energy, water resource and resource consumption. It is also the most promising, most qualified, and most urgent industry that needs to develop a recycling economy.

- This CE approach in the petrochemical industry necessitates a compliance with the requirements of $\mathrm{CE}$ development, using $\mathrm{CE}$ development principles and theories as a guide constructed by a CE evaluation index system.

- The selection of 24 quantitative indicators covering a range of the aspects, including resource utilization, resource recycling, and waste disposal. All these weight indicators have to effectively, objectively, and accurately determine the development of a CE in the petrochemical industry from 2014 to 2017 in China.

\subsection{Biological Drying Technology at the Context of Organic Waste Management}

Biological drying (thereafter named as biodrying) is an energy-effective technology for converting organic waste into solid recovered fuel (SRF). In biodrying, water removal is achieved using metabolic heat produced from microbiological degradation of organics and forced airflow to promote heat and 
mass transfer. Wastes that were treated by biodrying included MSW, sewage sludge, manure, pulp mill sludge, and a combination of food waste and sewage sludge [44]. Regarding the nature of the waste, biodegradability and heat contents need to be considered for designing a biodrying process. Obviously, if the wastes are not biodegradable, biodrying cannot be used [44].

Although composting processes have been extensively modelled, limited works have been published on the modelling of biodrying processes. Besides composting, it is also well known that microbial communities continually change to adapt to a newly-evolved environment. As known, substrates and process conditions determine the density and composition of microbial communities, and temperature is the major factor affecting metabolic activities. From a modelling perspective, deployment of good models ensures the energy balances of the biodrying processes, improves the configurations of biodrying reactors, explores the optimum design criteria which cannot be clearly identified through experiments, being especially devoted for coupling mass and heat transfer mechanisms [44]. Modelling can also determine the controlling drying rate, drying kinetics, the prediction of biodrying performance; coupled with different microorganisms, temperature, moisture content, and concentrations of growth substrates change during the processes [44]. Additionally, regulatory controls, such as the EU waste incineration directive (WID), set prescriptive limits for heavy metal emissions to the atmosphere. Finally, commercial full-scale biodrying plants have been developed during the last two decades in Europe, where the reduction of health risks, environmental impact, and off-gases of biodrying plants should be properly managed because organic contaminants, ammonia, bioaerosols, fine particulates, and odor-causing substances co-exist in the exit gas [44].

Hydrolysis and fermentation are the most significant production processes of biofuel from organic waste. The ultrasonic effect can accelerate the hydrolysis process by cracking lignin, cellulose, hemicellulose, and therefore shorten temperature and timing processes. Moreover, the glucose yield is higher and the cavitation and acoustic phenomena which are simultaneously happening increase all chemical reaction levels [45].

Finally, the future marketable perspective of vermiculture and cocoon seems to be a promising research orientation in conjunction with the development of innovative business models that take into account all stages of the process [46-48].

\section{Organic Waste Management at the Context of Circular Economy}

At a wider managerial framework, organic waste management can be framed in wider waste management, which impacts climate change in the following five forms: landfill methane emissions, reduction in industrial energy use, energy recovery from waste, carbon sequestration in forest recycling paper, and energy used in the long-distance transport of waste. In this regard, national instruments have been put in force, in agreement with the Climate Change Submit in 2015 to reduce greenhouse gas emissions, including the management of its waste among the measures [10].

Organic matter is composed of biodegradable components such as food scraps, yard waste (leaves, grass, brush), and wood. It has been shown that poor waste management leads to environmental threats and a proliferation of diseases. Organic matter is one of the most severe hygiene and environmental problems, especially among developing countries in Africa, since it generates bad odors and disease vectors, such as malaria. Besides, low-income countries have the highest proportion of organic waste, being mainly generated in cooking and food services (waste composition reaches up to $60 \%$ organic matter). In this context, composting production has proven to be the best option to introduce the organic fraction into the CE model, because compost can be used for the care of green areas, while biogas production would supplement localized energy production [10]

Nowadays, due to the increasing gap between environmental sustainability and economic growth, the potential of waste biorefineries in developing countries as a solution to current waste disposal problems and as facilities to produce fuels, power, heat, and value-added products, is a contentious issue [23]. Waste disposal in a sustainable manner is still in its infancy in most developing countries since the high generation rates of organic waste and its disposal to open dumpsites or non-sanitary 
landfills have resulted in adverse environmental, economic and social problems. The selection of waste to energy (WtE) technologies depends on regional waste characterization, being potential feedstock in various biorefinery technologies such as fermentation, anaerobic digestion (AD), pyrolysis, incineration, and gasification, while alternative fuels can be found in non-food feedstocks [24].

From an environmental viewpoint of waste biorefineries, the environmental benefits are in the form of reduced landfilling and mitigating its detrimental impact on the environment and public health, an advanced agriculture sector, numerous greener products, and renewable energy production. [24,49,50]. Three factors determine the degree that materials are suitable for a circular design, namely the degradation of the material's quality, the technical recyclability of the quantity of the recycled material, and the recoverability of mass and energy based on European Directive 2005/64/EC [20].

\subsection{Anaerobic Digestates}

The combination of eco-innovative technologies with anaerobic co-digestion allows the production of biomethane from sludge coming from water treatment plants, which is considered as a sustainable, ecological and innovative alternative to traditional sludge disposal methods [39] and offers financial and economic interest through energy production and essential nutrient production that excludes toxic elements [25]. Moreover, through membrane separation technology to adjust the C:N:P ratio, the $\mathrm{CE}$ approach may be combined as a commodity in an attractive proposition of algae biomass, since the latter is a rich source of protein and lipids and many other useful compounds with bioactive properties which offer proven applications in the pharmaceutical and cosmetics industries [25]. The key-aspects of AD full development include economic aspects, different concepts of utilization, logistics and population issues and social acceptance with regards to the distance to inhabited areas [51].

\subsection{Key Indicators of Organic Waste Management at the Context of Circular Economy}

In Figure 4, an important advantage of CE systems is depicted, namely, to keep the added value in products for as long as possible and eliminate waste [52]. The reuse of a product after its initial use is completely done, but the interactions with the ecosphere have to be considered. The driving factors are varied-from low recycling rates and demand issues to the lack of infrastructure and viable economics regarding the dissipative use. However, in certain cases, scrap is being utilized much more effectively, providing large amounts of secondary supply [52].

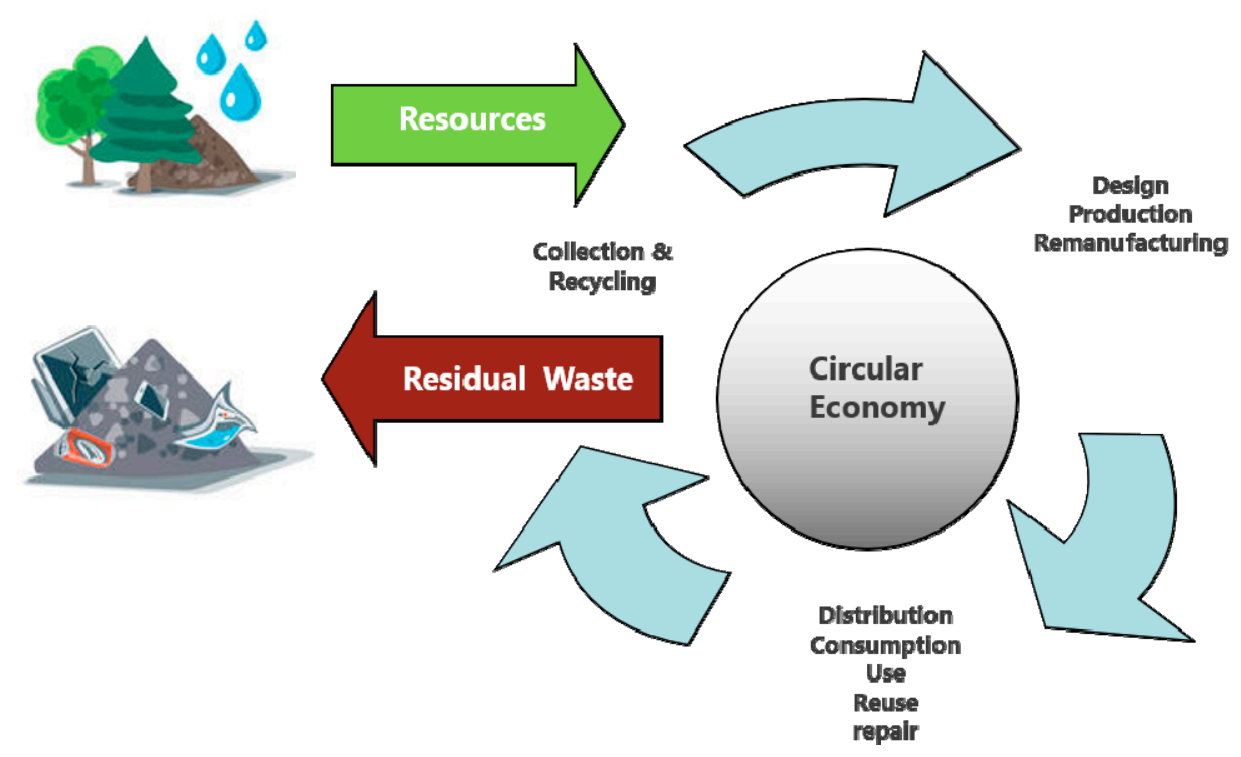

Figure 4. The composition of the CE processes. Source: adapted and modified from Smol et al. [52] p. 46. 


\section{Agrarian Development at the Context of Circular Economy}

CE operability is considered as an economic system which is designed to regenerate itself. For example, the functionality of $\mathrm{CE}$ in the framework of industrial economy is fully regenerative since it supports the active optimization of its operating systems [52]. However, the critical consideration of CE in the frameworks of technosphere and biosphere unveil complex implications [53]. The pronounced role of effecting the agrarian principles on CE to agriculture is noteworthy, playing a decisive role at the international, political, and economic agendas. This argumentation is also notable in the Food and Agriculture Organization (FAO) forecasting for 2050, showing the imperative need of a steady increase in global agricultural production by $70 \%$, reaching the astonishing increase of almost $100 \%$ in developing countries, in order to satisfy the global nutrition demand at a subsistence level [53].

\subsection{Key Indicators of Agrarian Development at the Context of Green Economy}

The key indicators of agrarian development at the context of green economy commonly involve managerial costs, energy production, and food management, especially in nutrition feeding. Regarding management costs, it is noteworthy that these types of costs incurred in the lifetime of the plant, involving: (a) ordinary operational costs, which are referred to as normal plant management under certain characteristics of the plants and their agricultural products that are directed to consumption; (b) extraordinary operational costs, which are valued as periodic and necessary costs in improving system performance and are referred to as the characteristics and the type of planting. implant. The timeline of such a type of intervention is commonly extended, at about 10 years [53].

With energy issues, the main concern regards energy production. Particularly, energy consumption is directly related to great economic potential in the case where a company achieves an increase its energy output at higher levels than that of which the planting needs, thus, selling the surplus can transform waste into a value-added energy resource and it can generate a revenue source for planting. Besides, circularly-operated companies benefited highly from the current regulatory system. Besides energy benefits, companies can gain social benefits, such as attaining a well-known and prestigious public image, since in the present socio-managerial context any investment in renewable resources is certainly a choice of pronounced environmental-sustainability and social impact [53].

As to food management, it is noteworthy that, except for mineral-phosphorus materials that can be recovered from wastewater, there are further recovery and recycling options that enable sustainable nutrient management, especially towards organic waste and their recycling choices. In this respect, the key indicators of energy efficiency, synergies, and cost play a determining role in the implementation of integrative managerial solutions, instead of deciding on the development of fancy parallel (infra)structures [54]. Thus, the nutrients exploitation would play a significance role under some circumstances, fostering closer collaboration and synergies to create value in different sectors [55].

\subsection{Key Indicators of Agrarian Development in the Context of Agri-Food}

In the context of $\mathrm{CE}$, agri-food products would support significant applicability perspectives. Particularly since waste volumes are generated during at each distinct phase of the agri-food supply chain, from production to consumption, it is anticipated that a close-looped supply chain of agri-food can alleviate environmental depletion and the economic burden resulting from food waste disposal. Such a CE model is characterized by usefulness, under the precondition that companies which apply such circular-oriented strategic planning can cope with the challenges offered. In parallel, on the consumption side, it is critical to adapt to a new way of thinking, which can increase the efficiency of food processing and the sustainable reuse of by-products, wastes, and residues, under the principles of bio-economy. Moreover, the reusing organic residues as fertilizers can contribute to feasible soil restoration and prevention ongoing soil erosion [55,56]. 


\section{Food Waste Management in the Context of Circular Economy}

\subsection{Food Waste Management and Treatment Hierarchy}

In developed countries, generated food waste (FW) is twofold of the food produced in the developing ones. Therefore, it is of a paramount importance to deal with those impacts in present and future waste management, considering FW to be a resource divertible from landfilling [16]. Thus, the profound opportunity of the CE concept, as depicted in Figure 5, is a viable way to produce renewable energy sources and materials [26], toward a holistic understanding of the role of design in such a way [2].

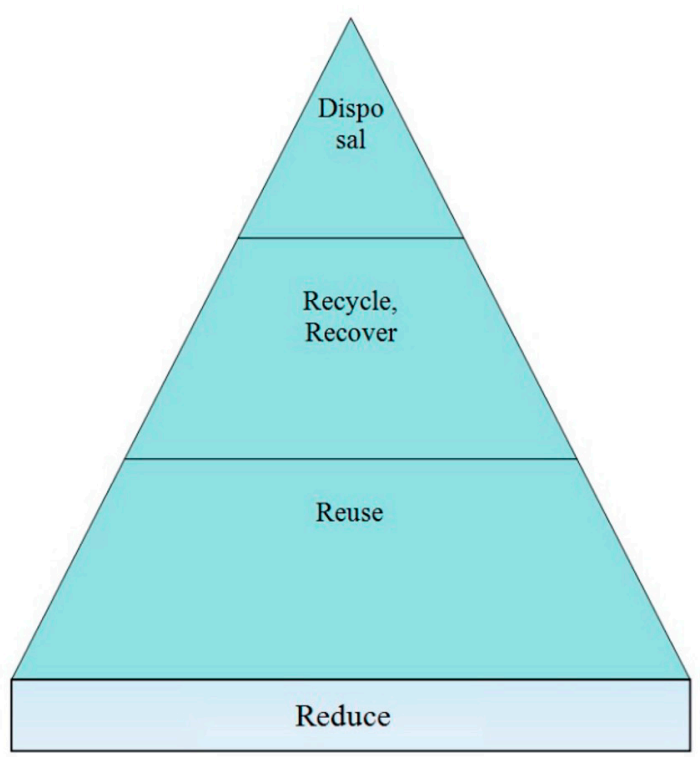

Landfilling, Thermal treatment without energy recovery

Landspreading, Thermal treatment with energy recovery, Composting, Anaerobic Digestion, Extraction of compounds, Industrial uses

Animal feed, Redistribution of human consumption

Prevention of food waste generation

Figure 5. Waste management and treatment hierarchy and corresponding technologies or actions. Source: adapted and modified from Ingrao et al. [26] p. 871.

Contrary to the common sense that food waste management deployed through $\mathrm{CE}$ is ideally managed by multinational companies, family businesses have perceived those circumstances when social cohesion is disrupted and environmental problems are unveiled, being especially alarming, as the development of theories of functionality, ecology, and development are incorporated through the lens of sustainability. Subsequently, family businesses can analyze the relationship developed between companies and their stakeholders, defined as groups or individuals who can affect or be affected by the achievement of a corporation's purpose. Then family businesses recognize their responsibility and respond by implementing new environmental policies or regulations, further adopting socio-emotional values to foster the transition to more sustainable production systems through the CE context. In this respect, the reasons why family firms' transition to a CE based on the socio-emotional wealth (SEW) theory was verified in a food retail leader in the Spanish market [18].

SEW is composed of three main dimensions, acting as motivation that speeds up the implementation of CE in family businesses. The first dimension is family prominence, unveiling the importance of how the family as a business owner is perceived by the community. The second dimension is family continuity, unveiling the importance of making decisions based on the sustainability of the family business and desire to maintain family ownership and management. The third dimension is family enrichment, indicating the significance of the desire to maintain family harmony through altruistic behavior, a distinctive characteristic of family-owned companies. Most family business decisions tend to preserve and enhance the family's SEW, since family businesses can behave differently from non-family businesses because non-economic factors dominate family firm business decisions for three reasons. Firstly, emotions are important in family-business relationships. Secondly, the family's 
own values, such as collectivism and feelings of responsibility, condition its behavior, commitment, and perpetuation. Thirdly, altruism motivates family businesses, which are generally immersed in their community, to protect their image and reputation. Through long-term, trans-generational perspective, family firms foster a strong desire to guard and protect its corporate reputation, thus, the family pursues the preservation of SEW, aiming at shaping the business to fit its (family) needs. The SEW framework highlights that one of the main objectives of family businesses is the search for continuity over time; the family will take the decisions required to achieve continuity. Business success and family balance are equally important to the sustainability of the company. The family will thus take the necessary steps to transition to a more environmentally sustainable model, such as CE, seeking the preservation of the family's SEW. In this context, SEW can be useful to practitioners, explaining realities and proposing ideas for real-world practice, the final theory is novel and relevant to the study of family businesses [18].

\subsection{Food Waste Management of Composting and Recycling}

In the relevant literature, the traditional technology of composting and the radically innovative approach of insects for animal feed were investigated by a developed structured questionnaire, regarding the perception of consumers in accepting novel CE technologies, as well as their willingness to be engaged with closed loops targeted at minimizing food waste [11] resulted in non-significance socio-economic variables (F test statistic: 0.134). Figures 6 and 7 below depict the corresponding loops for each group in household recycling without and with "insects as feed".

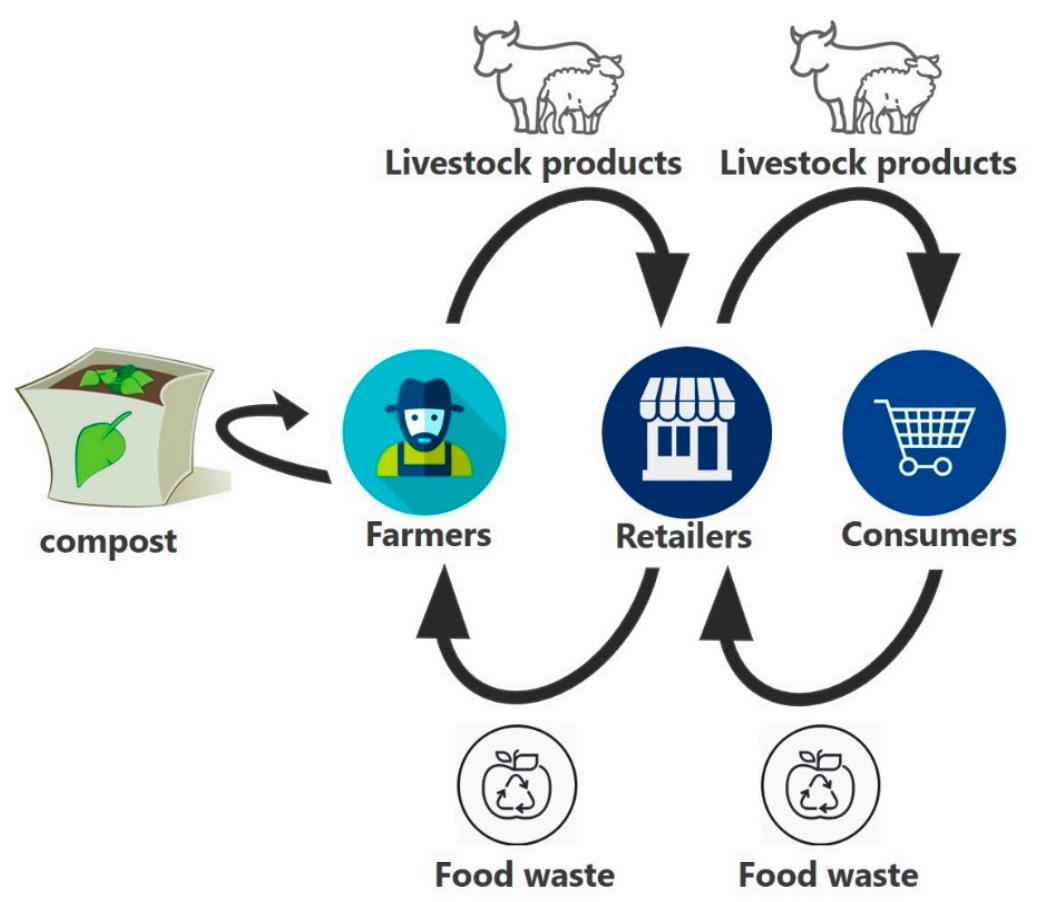

Figure 6. Circular paths concerning the use of the technology "compost" for recycling household food waste without insects as feed (solid line). Adapted from Source: Adapted and modified from Borrello et al. [11] p. 7/18. 


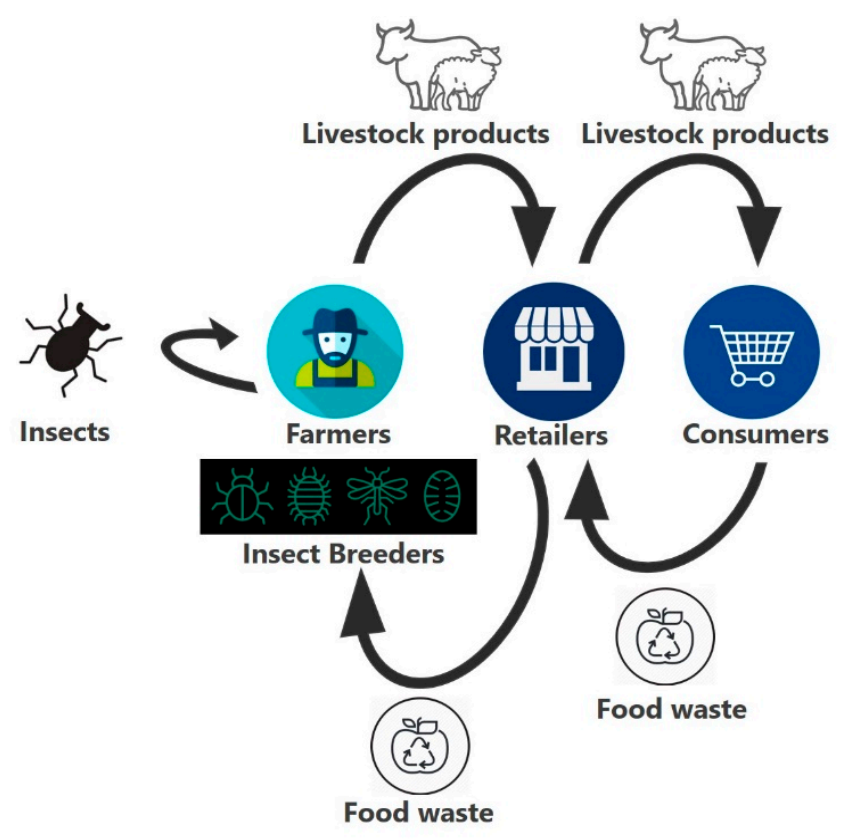

Figure 7. Circular paths concerning the use of the technology "insect feed" for recycling household food waste. Source: adapted and modified from Borrello et al. [11] p. 7/18.

Overall, based on the study of Borrello et al. [11], it was argued that (1) the treatment technology has no effect in the preference of the interviewees, (2) there is a problem of assuring the proper sorting by consumers of the organic food waste, and fining penalization on a discount reward for those consumers who deliver non-organic waste, (3) the correlation between income and food consumption of households is not sufficient to effect the reward proposed to reduce the quantity of animal products consumed, (4) there are limitations in model scalability, and (5) the corresponding population prefers to make personal effort towards the $\mathrm{CE}$ transition and less attached to monetary compensation.

\subsection{Key Indicators of Food Waste Management at the Context of Circular Economy}

EU policy supports waste reduction and recovery activities based on the waste hierarchy concept and the CE framework [16], setting the heat of combustion for energy production as a second option, and landfill disposal as the last option. Through the CE system of production and consumption, the highest value and quality is retained by the product value chain beside the energy efficiency $[57,58]$. In the context of FW management and in alignment with the principles of $\mathrm{CE}$, the results are influenced by the options of methodology and assumptions considered. On the other hand, AD seems to contribute and fit into the new vision of $\mathrm{CE}$, whereas materials and waste fluxes can benefit nature's cycles, by releasing valuable by-products to the fields, thus enhancing the cultivated ecosystems [57].

\section{Human Wastewater Management at the Framework of Circular Economy}

At the context of human wastewater stream nutrients, which are highly diluted by storm water and groundwater intrusion as well as other sources, the need for an innovative solution to reduce the environmental impact simultaneously with the increased demands in water, energy and food, is a necessity $[59,60]$. According this, domestic wastewater can potentially contribute to the nexus of water, energy and plant nutrient supply, with regard to the CE design [61,62]. Many blackwater technologies treatment of novel concepts are stressed out, being in an infant stage to date [61]. For example, CE consideration of closing the loop in domestic wastewater treatment for valuable nutrients such as liquid $\mathrm{N}, \mathrm{P}$ and $\mathrm{K}$, not only positively impacts the environmental pollution but may also supply liquid fertilizers for local biomass production and reduce the high-energy intensive Haber-Bosch process used for fertiliser production [61]. 
Key Indicators of Blackwater Management at the Context of the Circular Economy

An integrated approach in wastewater treatment contributes to a thorough and sustainable CE. The concept of restoration and regeneration at the source may allow for a more specific treatment and selective removal systems for the control of pathogens and micro-pollutants at the source, whilst the anaerobic digestion of source-separated blackwater combined with filtration and UV have resulted in high quality without compromising public health and the environment [61].

\section{Discussion}

\subsection{Developmental Strategies and Socio-Environmental Impact in the Context of the Circular Economy}

CE strategy is versatile enough to offer feasible potentials that offset virgin material demand and make provision for secondary supply, raw materials, alloys (recycling), parts (remanufacturing), and products (reuse). This CE feature is especially advantageous against supply restrictions where new materials are not readily available. Of particular importance are the following advancements: (a) the elimination of socio-political supply risk potentially divulged, while ensuring the supply of raw materials, parts, and products of domestic or industrial feedstock, and (b) the optimization of closed loop reverse supply chains. Such an approach can sustain competitive advantage to firms, enhancing profits and establishing brand reputation [52].

Another important feature of CE strategy is directed at dematerialization, which supports resource efficiency goals. This feature is feasible in various ways which involve a shift-case toward service-based economies. This managerial modification can be directed to service-based economies, owing to the development of technologies which support and ensure virtual services while enhancing global access to such technologies. It is also noteworthy that the implementation of advanced circularity principles is challenging the transition to service-based economies. Therefore it is an unavoidable reality that such a transition can be certainly be achieved among well-developed countries, while leaving behind and/or shifting manufacturing among countries of less developed circularity goals [52].

Besides the aforementioned dematerialization, diversification is also a key feature of industrial ecology (IE) that is readily applicable to the context of CE. Specifically, diversification can manage network expansion, having strong potential to strive for additional circularity pathways. In this respect, additional network nodes in the supply chain can strengthen dense connections which enable circularity within the whole system [52].

Furthermore, these strategies are indirectly and positively affecting the operability of firms. The main effect of these strategies regards the standardization of metrics in reducing supply chains risks [52]. Multifaceted economic, environmental, and social valuation of customer needs could be further materialized in terms of redesigning changes in business models and shifting from selling products, in the context of sustainable consumption and production (SCP). Critical indicators of SCP functionality include the time dimension (i.e., now and in the future), the utility preference, along with existing sunk costs [14,63].

\subsection{Discussion on Terminology Instruments and CE Models}

It is noteworthy that during the last decade, the aforementioned concepts of $\mathrm{BE}, \mathrm{CE}$, and GE and their relation to the goals directed at developing a sustainable economy have impacted political, academic, social, and entrepreneurial interest. The importance of measuring circularity is linked to measuring the effects of the CE in terms of profitability, job creation, and environmental impact. A proposed measure can be based on the economic value of the parts of a product. Besides, considering the environmental aspects of the analysis, a set of indicators can be designed to evaluate the efficiency of specific processes in CE models, such as efficiency in the use of resources, waste minimization and conversion. Future research is in alignment with different measures, enabling entrepreneurs to implement cleaner production, minimizing emissions along with raising competitiveness. Moreover, there is still room for further methodological improvements to better analyze the most appropriate 
indicators and to establish homogeneous and applicable database criteria in different situations and countries. Therefore, researchers can accurately evaluate a wide spectrum of different strategies promoted [7]. At another study, these promoted strategies can be classified under the following evaluation criteria [9].

- Product Lifecycle Stages: implying those lifecycle phases (i.e., beginning, middle, or end of life) which are considered for CE evaluation;

- Variables: implying types of variables (declined in energy, material, and other resources) which are considered and measured;

- Circularity Degree: implying the economic, environmental, or social perspectives used to analyze variables in the methodologies.

Research focus on the environmental level have led researchers to be directed towards variables involved in the circular systems, considered by either differentiating among materials (constituting the system to be delivered), energy and other resources (used to produce the product or system; not undermining analysis on final output pollution) or by considering a combination of them. Again, research focus on only one element confirms the importance of such type of variables in circularity performance, since a continuous flow of technical and biological materials through the "value circle" is considered in CE [9]. Generally, while literature confirms that circular models can be measured by taking care of different aspects, such models have been structured to evaluate all the possible variables involved in the system, running through almost the entire lifecycle. Indeed, in this case, the development phase leaves room for the following lifecycle stages-from production through to use, system operation and service delivery, up to disposal [9].

Again, coordination among all stakeholders is essential. For this reason, future research could be directed to find the most appropriate way to disseminate this theoretical knowledge, to promote the exchange of information between companies and to describe experiences from different parts of the world and varied institutions to broaden knowledge and increase collaboration on the studied topics. A challenging issue would be the analysis of corporate information among those companies that incorporate new management strategies related to these issues, to motivate and encourage other companies to take these models as references [7].

However, there is still a long way to go in implementing case studies and evaluating the economic impact of these concepts. Therefore, the need to promote, encourage, and to support companies in implementing cleaner production and to approach a more sustainable path, must predominated. It is also useful to draw upon the policies, strategies, case studies and the business models of companies that seek a more sustainable path. This fact is significant, since the exploration of sustainability issues, government regulations, and strategic policies, can enable organizations to grasp new opportunities, and to evaluate the impact of implementing them and move towards the objectives of a more sustainable system. However, there is still a long way to go in terms of business implementation and evaluation of the economic measurement of the impacts $[7,64-66]$.

\section{Conclusions}

\subsection{Current Situation and Feasibility Propositions of Socio-Environmental Significance}

The CE is conceptually connected to the prospect of a cultural change in consumption behavior. Since the role of public stakeholders is crucial, the educational process entails widespread awareness in society. The design according circular principles requires reverse logistics consideration to promote cost-efficiency and better quality in dedicated collection areas through an incentivized system to return materials and to recover energy flows. There is considerable rising impact from negative externalities which has to be analyzed in alignment with the investment environment and risks and where it conflicts with the principle of sustainability. The long term involvement in circular business embeds financially efficient business and creates new irreversible sunk costs to overcome existing salvage 
values. The significant effort from all the stakeholders has to be sufficiently incentivised, with the consumers included. Ecological awareness, psychological incentives, political and economic initiatives may be designed. The effectiveness of the instruments and the mix of strategies used for the transition to $C E$ in micro, meso, and macro levels is a challenging task regarding the specific solutions in each situation faced.

\subsection{Future Research Orientations}

There are still many issues which lead to negative ecological impact, deriving from the fundamental assumptions of $\mathrm{CE}$, which are worthy of further investigation. Since our perception on the effects of substance flows on the environment is continuously growing, there are serious drawbacks about the unlimited return of nutrients in the ecosphere without problems. Again, the creation of a zero waste economy would cost enormous quantities of energy too, and the design principle on the equality of food and waste conflicts with the downgrading principle of all production processes. This also entails raising environmental awareness among local populations and authorities while it has been signified that more business analysis and market studies are also vital for the correct implementation of a waste management plan based on CE models. Therefore, future research orientations could consider that achievement of zero waste is associated with market requirements, logistics, and other aspects of socialized lifestyle, including critical changes in education, culture, public policies, and waste mitigation, including designing resource minimization in manufacturing, energy balance of production, decreased water and carbon footprints [10].

Long-term orientation and desire to preserve company reputation makes the analysis of sustainability issues especially important and the CE model advances this effort towards the conservation of resources, the use of sustainable energy, and the reuse of components, all valued as key factors in a new form of future entrepreneurial competition [18]. In research design, information concerning the carbon footprint of companies, obtained mainly from the energy consumption in the entrepreneurial infrastructure, can be explicitly derived by the use of gases and logistic activities. Such information can be verified by calculating the ratio intensity of $\mathrm{CO}_{2}$, which links emissions (numerator) and incomes (denominator) [18].

The social dimension in the design of CE policies is also placed in the core of sustainability and consumption behaviour states in the forefront of the research. In the literature, a lack of discussion on the social issue has been identified. The complexity of the CE has also been transforming problems to opportunities regarding regulated waste management, the modelling analysis, and the trade-off proposals and policies for municipalities. The recycling chain in cities and urban areas is benefited by the continuous organization as an effective market. From the procedural viewpoint, further developments and marketable perspectives of the technologies have to be researched in terms of the most efficient and effective waste management regarding all determining parameters of the processes.

It is indicatively noted that creating legislative initiatives patterned on action adaptation from the developed economies to the developing ones, where $C E$ framework can reduce or remove the negative externalities that bad waste management entails, while creating a new and more sustainable production model that can serve as a reference strategy of waste management. Such strategy could comply with the following three objectives within the social responsibility orientation: improving health and environmental conditions, deployment of research projects related to waste recycling and environmental sustainability, as well as the promotion of environmental awareness in the urban areas of interest [10].

Author Contributions: G.L.K. and V.C.K. contributed to the deployment of the literature review, the structure of the research analysis, the discussion deployed, and the conclusions drawn. M.Z. contributed to the development of technical analysis, A.M. contributed in writing and remarks' clarification, and K.G.A. supervised the review.

Funding: This research received no external funding.

Conflicts of Interest: The authors declare no conflict of interest. 


\section{References}

1. Geissdoerfer, M.; Savaget, P.; Bocken, N.; Jan Hultink, E. The Circular Economy-A New Sustainability Paradigm? J. Clean. Prod. 2017, 143, 757-768. [CrossRef]

2. De los Rios, I.C.; Charnley, F.J.S. Skills and capabilities for a sustainable and circular economy: The changing role of design. J. Clean. Prod. 2017, 160, 109-122. [CrossRef]

3. Tukker, A.; Tischner, U. Product-services as a research field: Past, present and future. Reflections from a decade of research. J. Clean. Prod. 2006, 14, 1552-1556. [CrossRef]

4. Tukker, A. Product services for a resource-efficient and circular economy-A review. J. Clean. Prod. 2015, 97, 76-91. [CrossRef]

5. Merli, R.; Presiozi, M. Acabora Alesia How do scholars approach circular economy? A systematic literature review. J. Clean. Prod. 2018, 178, 703-722. [CrossRef]

6. Ghosh, S.K.; Agamuthu, P. Circular economy: The way forward. Waste Manag. Res. 2018, 36, 481-482. [CrossRef]

7. Gregorio, V.F.; Pie, L.; Terceno, A. A Systematic Literature Review of Bio, Green and Circular Economy Trends in Publications in the Field of Economics and Business Management. Sustainability 2018, 10, 4232. [CrossRef]

8. Grigoropoulos, C.J.; Doulos, L.T.; Zerefos, S.; Tsangrassoulis, A.; Bhusal, P. Estimating the benefits of increasing the recycling rate of lamps from the domestic sector: Methodology, opportunities and case study. Waste Manag. 2020, 101, 188-199. [CrossRef]

9. Sassanelli, C.; Rosa, P.; Rocca, P.; Terzi, S. Circular economy performance assessment methods: A systematic literature review. J. Clean. Prod. 2019, 229, 440-453. [CrossRef]

10. Salguero-Puerta, L.; Leyva-Diaz, J.C.; Cortes-Garcia, F.J.; Molina-Moreno, V. Sustainability Indicators Concerning Waste Management for Implementation of the Circular Economy Model on the University of Lome (Togo) Campus. Int. J. Environ. Res. Public Health 2019, 16, 2234. [CrossRef]

11. Borrello, M.; Caracciolo, F.; Lombardi, A.; Pascucci, S.; Cembalo, L. Consumers' perspective on circular economy strategy for reducing food waste. Sustainability 2017, 9, 141. [CrossRef]

12. Birol, E.; Das, S. Estimating the value of wastewater treatment: The case of River Ganga, India. J. Environ. Manag. 2010, 91, 2163-2171. [CrossRef] [PubMed]

13. Gaustad, G.; Krystofik, M.; Bustamante, M.; Badami, K. Circular economy strategies for mitigating critical material supply issues. Resour. Conserv. Recycl. 2018, 135, 24-33. [CrossRef]

14. Kapsalis, V.C.; Kyriakopoulos, G.L.; Aravossis, K.G. Investigation of Ecosystem Services and Circular Economy Interactions under an Inter-organizational Framework. Energies 2019, 12, 1734. [CrossRef]

15. Masullo, A. Organic wastes management in a circular economy approach: Rebuilding the link between urban and rural areas. Ecol. Eng. 2017, 101, 84-90. [CrossRef]

16. Wang, J. Study on construction and application of circular economy evaluation index system in petrochemical industry. Chem. Eng. Trans. 2018, 66, 1423-1428. [CrossRef]

17. Thomas, L.; Oldfield, E.W. The implications of stakeholder perspective for LCA of wasted food and green waste. J. Clean. Prod. 2018, 170, 1554-1564. [CrossRef]

18. Nunez-Cacho, P.; Molina-Moreno, V.; Corpas-Iglesias, F.A.; Cortes-Garcia, F.J. Family Businesses Transitioning to a Circular Economy Model: The Case of Mercadona. Sustainability 2018, 10, 538. [CrossRef]

19. Aravossis, K.G.; Kapsalis, V.C.; Kyriakopoulos, G.L.; Xouleis, T.G. Development of a Holistic Assessment Framework for Industrial Organizations. Sustainability 2019, 11, 3946. [CrossRef]

20. Iacovidou, E.; Velis, C.A.; Purnell, P.; Zwirner, O.; Brown, A.; Hahladakis, J.; Millward-Hopkins, J.; Williams, P.T. Metrics for optimising the multi-dimensional value of resources recovered from waste in a circular economy: A critical review. J. Clean. Prod. 2017, 166, 910-938. [CrossRef]

21. Shukor, J.-A.; Omar, M.-F.; Kasim, M.-M.; Jamaludin, M.-H.; Naim, M.-A. Assessment of composting technologies for organic waste management. Int. J. Technol. 2018, 8, 1579-1587. [CrossRef]

22. Kilkis, S.; Kilkis, B. Integrated circular economy and education model to address aspects of an energy-water-food nexus in a dairy facility and local contexts. J. Clean. Prod. 2017, 167, 1084-1098. [CrossRef]

23. Zamparas, M.; Kapsalis, V.; Kyriakopoulos, G.; Aravossis, K.; Kanteraki, A.; Vantarakis, A.; Kalavrouziotis, I.K. Medical waste management and environmental assessment in the Rio University Hospital, Western Greece. Sustain. Chem. Pharm. 2019, 13, 100-163. [CrossRef] 
24. Nizami, A.S.; Rehan, M.; Waqas, M.; Naqvi, M.; Ouda, O.K.M.; Shahzad, K.; Miandad, R.; Khan, M.Z.; Syamsiro, M.; Ismail, I.M.I.; et al. Waste biorefineries: Enabling circular economies in developing countries. Bioresour. Technol. 2017, 241, 1101-1117. [CrossRef]

25. Stiles, W.A.V.; Styles, D.; Chapman, S.P.; Esteves, S.; Bywater, A.; Melville, L.; Silkina, A.; Lupatsch, I.; Fuentes Grünewald, C.; Lovitt, R.; et al. Using microalgae in the circular economy to valorise anaerobic digestate: Challenges and opportunities. Bioresour. Technol. 2018, 267, 732-742. [CrossRef]

26. Ingrao, C.; Faccilongo, N.; Di Gioia, L.; Messineo, A. Food waste recovery into energy in a circular economy perspective: A comprehensive review of aspects related to plant operation and environmental assessment. $J$. Clean. Prod. 2018, 184, 869-892. [CrossRef]

27. Ghisellini, P.; Protano, G.; Viglia, S.; Gaworski, M.; Setti, M.; Ulgiati, S. Integrated agricultural and dairy production within a circular economy framework. A comparison of Italian and Polish farming systems. J. Environ. Account. Manag. 2014, 2, 367-384. [CrossRef]

28. De Man, R.; Friege, H. Circular economy: European policy on shaky ground. Waste Manag. Res. 2016, 34, 93-95. [CrossRef]

29. Zamparas, M.; Kapsalis, V.C.; Kanteraki, A.E.; Vardoulakis, E.; Kyriakopoulos, G.L.; Drosos, M.; Kalavrouziotis, I. Novel composite materials as P-adsorption agents and their potential application as fertilizers. Glob. Nest J. 2019, 21, 48-57.

30. Bekchanov, M.; Mirzabaev, A. Circular economy of composting in Sri Lanka: Opportunities and challenges for reducing waste related pollution and improving soil health. J. Clean. Prod. 2018, 202, 1107-1119. [CrossRef]

31. Ahmedelbdawy, W.M.A.; Abuelnuor, A.A.A.; Omara, A.A.M.; Adil Taha, S. An experimental study on landfill technology to produce an alternative source of energy from organic waste. In Proceedings of the International Conference on Computer, Control, Electrical, and Electronics Engineering (ICCCEEE 2018), Khartoum, Sudan, 12-14 August 2018.

32. Gallardo, A.; Carlos, M.; Bovea, M.D.; Colomer, F.J.; Albarrán, F. Analysis of refuse-derived fuel from the municipal solid waste reject fraction and its compliance with quality standards. J. Clean. Prod. 2014, 83, 118-125. [CrossRef]

33. Panahandeh, A.; Asadollahfardi, G.; Mirmohammadi, M. Life cycle assessment of clinker production using refuse-derived fuel: A case study using refuse-derived fuel from Tehran municipal solid waste: Reducing emissions and conserving fossil fuel in cement making and making beneficial use of solid waste. Environ. Qual. Manag. 2017, 27, 57-66. [CrossRef]

34. Chiemchaisri, C.; Charnnok, B.; Visvanathan, C. Recovery of plastic wastes from dumpsite as refuse-derived fuel and its utilization in small gasification system. Bioresour. Technol. 2010, 101, 1522-1527. [CrossRef] [PubMed]

35. Liu, Z.; Wang, H.-Q.; Zhou, Y.-Y.; Liu, J.-W.; Zhang, X.-D.; Hu, G.-W. Effect of microwave chlorine depleted pyrolyzate on the combustion characteristics of refuse derived fuel derived from package waste. Waste Manag. 2018, 82, 1-8. [CrossRef] [PubMed]

36. Edo, M.; Budarin, V.; Aracil, I.; Persson, P.-E.; Jansson, S. The combined effect of plastics and food waste accelerates the thermal decomposition of refuse-derived fuels and fuel blends. Fuel 2016, 180, 424-432. [CrossRef]

37. Manya, J.J.; Garcia-Ceballos, F.; Azuara, M.; Latorre, N.; Royo, C. Pyrolysis and char reactivity of a poor-quality refuse-derived fuel (RDF) from municipal solid waste. Fuel Process. Technol. 2015, 140, 276-284. [CrossRef]

38. Younan, Y.; van Goethem, M.W.M.; Stefanidis, G.D. A particle scale model for municipal solid waste and refuse-derived fuels pyrolysis. Comput. Chem. Eng. 2016, 86, 148-159. [CrossRef]

39. Baldasso, E.; Andreasen, J.G.; Mondejar, M.E.; Larsen, U.; Haglind, F. Technical and economic feasibility of organic Rankine cycle-based waste heat recovery systems on feeder ships: Impact of nitrogen oxides emission abatement technologies. Energy Convers. Manag. 2019, 183, 577-589. [CrossRef]

40. Mohammadkhani, F.; Shokati, N.; Mahmoudi, S.M.S.; Yari, M.; Rosen, M.A. Exergoeconomic assessment and parametric study of a Gas Turbine-Modular Helium Reactor combined with two Organic Rankine Cycles. Energy 2014, 65, 533-543. [CrossRef]

41. Shokati, N.; Mohammadkhani, F.; Yari, M.; Mahmoudi, S.M.S.; Rosen, M.A. A comparative exergoeconomic analysis of waste heat recovery from a gas turbine-modular helium reactor via organic rankine cycles. Sustainability 2014, 6, 2474-2489. [CrossRef] 
42. Kazmierczak, U.; Blachowski, J.; Gorniak-Zimroz, J. Multi-Criteria Analysis of Potential Applications of Waste from Rock Minerals Mining. Appl. Sci. 2019, 9, 441. [CrossRef]

43. Wozniak, J.; Pactwa, K. Overview of Polish Mining Wastes with Circular Economy Model and Its Comparison with Other Wastes. Sustainability 2018, 10, 3994. [CrossRef]

44. Yang, B.; Hao, Z.; Jahng, D. Advances in biodrying technologies for converting organic wastes into solid fuel. Dry. Technol. 2017, 35, 1950-1969. [CrossRef]

45. Irawan, D.; Arifin, Z. Glucose synthesis of organic waste with ultrasonic technology using chloride acid catalyst of hydrolysis process. Rasayan J. Chem. 2017, 10, 1302-1304.

46. Furlong, C.; Rajapaksha, N.S.; Butt, K.R.; Gibson, W.T. Is composting worm availability the main barrier to large-scale adoption of worm-based organic waste processing technologies. J. Clean. Prod. 2017, 164, 1026-1033. [CrossRef]

47. Naidoo, K.; Swatson, H.; Yobo, K.S.; Arthur, G.D. Boosting Our Soil With Green Technology: Conversion of Organic Waste Into "Black Gold". In Food Bioconversion-Handbook of Food Bioengineering; Academic Press: Cambridge, MA, USA, 2017; Chapter 15; pp. 491-510.

48. Lim, S.-L.; Lee, L.-H.; Wu, T.-Y. Sustainability of using composting and vermicomposting technologies for organic solid waste biotransformation: Recent overview, greenhouse gases emissions and economic analysis. J. Clean. Prod. 2016, 111, 262-278. [CrossRef]

49. Zamparas, M.; Kalavrouziotis, I.K. Healthcare waste management in Greece. The example of health region of Western Greece, Peloponnese, Epirus and Ionian Islands. Glob. Nest J. 2018, 20, 96-102.

50. Russo, A. Innovation and circular economy in water sector: The CAP group. In The Italian Water Industry; Springer: Cham, Switzerland, 2018; pp. 215-224. [CrossRef]

51. Rolewicz-Kalinska, A.; Oniszk-Popławska, A.; Wesołowska, J.; Rynska, E.D. Conditions for the development of anaerobic digestion technologies using the organic fraction of municipal solid waste: Perspectives for Poland. Environ. Dev. Sustain. 2016, 18, 1279-1296. [CrossRef]

52. Smol, M.; Kulczycka, J.; Henclik, A.; Gorazda, K.; Wzorek, Z. The possible use of sewage sludge ash (SSA) in the construction industry as a way towards a circular economy. J. Clean. Prod. 2015, 95, 45-54. [CrossRef]

53. Donia, E.; Mineo, A.M.; Sgroi, F. A methodological approach for assessing businness investments in renewable resources from a circular economy perspective. Land Use Policy 2018, 76, 823-827. [CrossRef]

54. Kabbe, C. Circular economy: Bridging the gap between phosphorus recovery and recycling. Phosphorus Recovery Recycl. 2018, 45-57. [CrossRef]

55. Molina-Sanchez, E.; Leyva-Diaz, J.-C.; Cortes-Garcia, F.-J.; Molina-Moreno, V. Proposal of Sustainability Indicators for the Waste Management from the Paper Industry within the Circular Economy Model. Water 2018, 10, 1014. [CrossRef]

56. Alcon, F.; Pedrero, F.; Martin-Ortega, J.; Arcas, N.; Alarcon, J.J.; de Miguel, M.D. The non-market value of reclaimed wastewater for use in agriculture: A contingent valuation approach. Span. J. Agric. Res. 2010, 8, 187-196. [CrossRef]

57. Borrello, M.; Lombardi, A.; Pascucci, S.; Cembalo, L. The seven challenges for transitioning into a bio-based circular economy in the agri-food sector. Recent Pat. Food Nutr. Agric. 2016, 8, 39-47. [CrossRef]

58. Korhonen, J.; Honkasalo, A.; Seppala, J. Circular economy: The concept and its limitations. Ecol. Econ. 2018, 143, 37-46. [CrossRef]

59. Jimenez-Rivero, A.; García-Navarro, J. Exploring factors influencing post-consumer gypsum recycling and landfilling in the European Union. Resour. Conserv. Recycl. 2017, 116, 116-123. [CrossRef]

60. Gianni, A.; Zamparas, M.; Papadas, I.T.; Kehayias, G.; Deligiannakis, Y.; Zacharias, I. Monitoring and Modeling of Metal Concentration Distributions in Anoxic Basins: Aitoliko Lagoon, Greece. Aquat. Geochem. 2013, 19, 77-95. [CrossRef]

61. Zamparas, M.; Drosos, M.; Deligiannakis, Y.; Zacharias, I. Eutrophication control using a novel bentonite humic-acid composite material Bephos ${ }^{\mathrm{TM}}$. J. Environ. Chem. Eng. 2015, 3, 3030-3036. [CrossRef]

62. Moges, M.E.; Todt, D.; Heistad, A. Treatment of source-separated blackwater: A decentralized strategy for nutrient recovery towards a circular economy. Water 2018, 10, 463. [CrossRef]

63. Zamparas, M.; Zacharias, I. Restoration of eutrophic freshwater by managing internal nutrient loads. A review. Sci. Total Environ. 2014, 496, 551-562. [CrossRef] 
64. Lakatos, E.S.; Cioca, L.-I.; Dan, V.; Ciomos, A.O.; Crisan, O.A.; Barsan, G. Studies and investigation about the attitude towards sustainable production, consumption and waste generation in line with circular economy in Romania. Sustainability 2018, 10, 865. [CrossRef]

65. Arabatzis, G.; Kyriakopoulos, G.; Tsialis, P. Typology of regional units based on RES plants: The case of Greece. Renew. Sustain. Energy Rev. 2017, 78, 1424-1434. [CrossRef]

66. Kyriakopoulos, G.L.; Arabatzis, G.; Tsialis, P.; Ioannou, K. Electricity consumption and RES plants in Greece: Typologies of regional units. Renew. Energy 2018, 127, 134-144. [CrossRef]

(C) 2019 by the authors. Licensee MDPI, Basel, Switzerland. This article is an open access article distributed under the terms and conditions of the Creative Commons Attribution (CC BY) license (http://creativecommons.org/licenses/by/4.0/). 